\title{
Current and emerging treatment options for the elderly patient with chronic kidney disease
}

\author{
This article was published in the following Dove Press journal: \\ Clinical Interventions in Aging \\ 15 January 2014 \\ Number of times this article has been viewed
}

\section{Robert G Fassett}

The University of Queensland School of Human Movement Studies, Brisbane, Queensland, Australia
Correspondence: Robert G Fassett The University of Queensland School of Human Movement Studies, Rm 535

Connell Building, St Lucia, 4072,

Queensland, Australia

Tel +6I $41939957 \mid$

Fax +6I 733656877

Email r.fassett@uq.edu.au
Abstract: The objective of this article is to review the current and emerging treatments of CKD prior to dialysis in the elderly. Worldwide, there are increasing numbers of people who are aged over 65 years. In parallel, there are increasing numbers of elderly patients presenting with chronic kidney disease (CKD), particularly in the more advanced stages. The elderly have quite different health care needs related to their associated comorbidity, frailty, social isolation, poor functional status, and cognitive decline. Clinical trials assessing treatments for CKD have usually excluded patients older than 70-75 years; therefore, it is difficult to translate current therapies recommended for younger patients with CKD across to the elderly. Many elderly people with CKD progress to end-stage kidney disease and face the dilemma of whether to undertake dialysis or accept a conservative approach supported by palliative care. This places pressure on the patient, their family, and on health care resources. The clinical trajectory of elderly CKD patients has in the past been unclear, but recent evidence suggests that many patients over 75 years of age with multiple comorbidities have greatly reduced life expectancies and quality of life, even if they choose dialysis treatment. Offering a conservative pathway supported by palliative care is a reasonable option for some patients under these circumstances. The elderly person who chooses to have dialysis will frequently have different requirements than younger patients. Kidney transplantation can still result in improved life expectancy and quality of life in the elderly, in carefully selected people. There is a genuine need for the inclusion of the elderly in CKD clinical trials in the future so we can produce evidence-based therapies for this group. In addition, new therapies to treat and slow CKD progression are needed for all age groups. Keywords: frailty, functional status, palliative care, elderly, dialysis, kidney transplantation

\section{Introduction}

Global population demographics are changing, and it is predicted that over the next few decades the number of people over 65 years of age will increase by a factor of three. In Australia, it is estimated that by 2050 the ratio of people aged over 65 years will be one in four. ${ }^{1}$ Parallel to this, there has already been a steady increase in the number of older people with chronic kidney disease (CKD) reaching end-stage kidney disease (ESKD) and requiring dialysis. ${ }^{2}$ In the United States, patients over 65 years of age represent $40 \%$ of the ESKD population. ${ }^{3}$ The incidence of ESKD in the elderly is also rising in Europe. ${ }^{4}$ However, while the ESKD population is well studied, there are limited numbers of studies in the non-dialysis CKD population that has restricted estimates of their numbers. From those studies available, older individuals with CKD are more likely to die, mainly from cardiovascular disease, rather than survive to progress to ESKD requiring dialysis or kidney transplantation. ${ }^{5}$ 
The elderly have unique health care requirements, as they are at increased risk of comorbidities that may result in frailty, reduced physical and cognitive function, and they are also often faced with complex psychosocial, financial, and transportation issues. ${ }^{6}$ It is estimated that almost half of 65-74-year-olds have five or greater chronic health conditions, and this may reach $70 \%$ once individuals are aged over 85 years (Table 1). ${ }^{7}$

Despite this, substantial longevity can be achieved with active medical management in many elderly patients with CKD. The plethora of medical conditions that represent the comorbidities of the aging person can now be treated, when required, with interventions such as coronary artery angioplasty and stenting, coronary artery bypass grafting, laser retinal and cataract surgery, corneal grafts, peripheral vascular and renal artery stents, open and transluminal aortic grafts, cardiac pacemakers, and implantable defibrillators. In addition, there are effective pharmaceutical treatments such as blood pressure (BP) control or lipid-lowering therapies such as statins and fibrates, which may enable the person to survive longer. However, ultimately, the next organs to fail are often the kidneys.

\section{Chronic kidney disease}

The diagnosis of CKD in the elderly, as with CKD in general, has been recently reviewed and updated by the Kidney Disease Improving Global Outcomes (KDIGO) group. ${ }^{8}$ However, within these guidelines, there are no specific recommendations regarding the early identification and management of the elderly with CKD. In fact, the current CKD classification system may overestimate the prevalence of CKD in the elderly. ${ }^{9}$ Within the new classification system, age-related cut-off points for the diagnosis of CKD are no longer recommended. ${ }^{10}$ This change was based on evidence that reduced estimated glomerular filtration rate (eGFR) and albuminuria predicted ESKD onset and mortality, irrespective of age. ${ }^{11}$ Therefore, the previous age dispensation has been removed, and the diagnosis of CKD in the elderly now requires the same criteria as in all age groups. ${ }^{8,12}$ The risks associated with reduced eGFR, such as cardiovascular disease risk, are believed to be just as important, irrespective of age. The risk of CKD increases with age, with approximately one-half of people with CKD stage $3 \mathrm{~A}$ developing it after 70 years of age. ${ }^{13}$ Being over 60 years of age is considered an independent risk factor for CKD in itself. ${ }^{12}$ However, recent data on CKD in the elderly suggests that the majority of these cases do not progress over a 2 -year period and few required dialysis. ${ }^{14}$ Further longitudinal data are required to better understand how kidney function behaves in association with age. Newly established longitudinal cohort studies and CKD registries will assist with filling the gaps in our knowledge.

\section{Assessment of kidney function in the elderly}

Kidney function declines with age ${ }^{15}$ at a rate of approximately $1 \mathrm{~mL} /$ minute $/ 1.73 \mathrm{~m}^{2}$ per decade after the age of 40 years or from $130 \mathrm{~mL} /$ minute $/ 1.73 \mathrm{~m}^{2}$ to $80 \mathrm{~mL} /$ minute $/ 1.73 \mathrm{~m}^{2}$ from $30-80$ years of age. ${ }^{16}$ The measurement and reporting of kidney function has evolved from using simple serum creatinine to complex formulae such as the Cockcroft-Gault, Modification of Diet in Renal Disease and CKD-Epi. The KDIGO currently use the CKD-Epi formula, as it is deemed more accurate. In addition, it is upon this formula that the new classification of CKD is based. However, it remains unclear how accurate these formulae are in the elderly, and a recent study found that in this context, these formulas should be used with caution and may misclassify CKD by one stage. ${ }^{17}$ One study recommended that the Cockcroft-Gault formula be calculated using the ideal body weight, and suggested it was the best performing formula used among the elderly. ${ }^{17}$ Other investigators have recommend the Modification of Diet in Renal Disease and CKD-Epi formulae in the elderly. ${ }^{18}$

\section{CKD registry and cohort studies}

CKD registries such as the Chronic Kidney Disease in Queensland (CKD.QLD) registry in Queensland in Australia have been established to describe the trajectory of CKD patients over time, as this has not been documented as well in pre-dialysis CKD as with ESKD. ${ }^{19}$ All patients with CKD aged over 18 years that are referred to CKD clinics in the Public Health system in Queensland are eligible to be consented and included in the CKD.QLD registry. Although in its early stages, the registry will provide longitudinal observational data on elderly CKD patients. ${ }^{19}$ Other CKD cohort studies such as the Chronic Renal Insufficiency Cohort (CRIC) Study Group, ${ }^{20}$ the Canadian Study of Prediction of Risk and Evolution to Dialysis, Death and Interim Cardiovascular Events Over Time, ${ }^{21}$ the National Kidney Foundation's Kidney Early Evaluation Program (KEEP), ${ }^{22}$ the Mild to Moderate Kidney Disease study, ${ }^{23}$ and the Chronic Renal Insufficiency in Birmingham (CRIB $)^{24}$ study have supplied longitudinal data on cohorts of CKD patients. An example cohort study conducted among the elderly is the United Kingdom National Health Service cohort, the first Grampian Laboratory Outcomes Mortality and Morbidity 
Study ${ }^{25}$ that consisted of 3,414 individuals with a median age of 78.6 years. The CRIC study had 3,612 participants enrolled with a mean age of 58.2 years, but the CRIB cohort had only 382 participants with a mean age of 61.5 years. ${ }^{20,24}$ Of participants aged $>65$ years, CKD prevalence was $44 \%$ in the KEEP study.22

\section{Investigation of elderly patients with CKD}

The investigation of elderly patients with CKD should be similar to that of their younger counterparts, and there should be no reluctance to perform kidney biopsies when indicated in the elderly, as there is no increased risk of complications. ${ }^{26}$

\section{Clinical trials}

The external validity and generalizability of clinical trials has been rightly questioned. ${ }^{27}$ In general, the elderly are underrepresented in clinical trials. ${ }^{28}$ As an example, in an analysis of cancer clinical trials, only $20 \%$ of those patients enrolled were over 70 years of age and only $9 \%$ over 75 years. ${ }^{29}$ When older patients are included in clinical trials, they are often in better health than the general elderly population because of the strict exclusion criteria seen in these trials. ${ }^{30}$ Consequently, there are few evidence-based guidelines addressing comorbidities in older persons..$^{31,32} \mathrm{In}$ addition, there is a distinct lack of evidence on how to treat the elderly with CKD because clinical trials in this setting usually have an exclusion criterion of $>70$ years or similar. Hence, the act of translating therapies of demonstrable value in clinical trials among younger individuals into practice in the elderly is quite problematic. Hence, often clinical decisions are based on evidence obtained from clinical trials in younger populations. ${ }^{33,34}$ As examples, in CKD, the Ramipril Efficacy In Nephropathy study, ${ }^{35}$ which assessed the angiotensin-converting enzyme (ACE) inhibitor, ramipril, in patients with CKD only included people between the ages of 18-70 years, and the Program for Irbesartan Mortality and Morbidity Evaluation study ${ }^{36}$ that assessed the angiotensin receptor blocker (ARB), irbesartan, in diabetic nephropathy included those aged 30-70 years. These trials formed the basis of evidence translation for the use of ACE inhibitors and ARB therapies in CKD. Therefore, there is a need for clinical trials that include older patients to assist in establishing therapeutic guidelines in this group.

Overall, there are no specific evidence-based guidelines available for the treatment of CKD in the elderly, particularly adults over 70 years of age, and guidelines are based on evidence obtained from younger populations.

\section{Conventional treatments of CKD}

\section{Hypertension}

The control and treatment of hypertension are the major available therapies to slow the progression of CKD. ${ }^{37}$ Studies that have included the elderly have demonstrated that the achievement of BP targets can reduce both cardiovascular events and the rate of decline in kidney function compared with those who did not reach their recommended BP targets. ${ }^{37}$ A large observational cohort study of elderly United States Veterans with CKD recommends optimal BP values of $130-159 \mathrm{mmHg}$ systolic, and $70-89 \mathrm{mmHg}$ diastolic. ${ }^{38}$ However, as with other aspects of the care of the elderly, there are a limited number of clinical trials that have assessed antihypertensive therapy. ${ }^{39}$

The Clinical Practice Guideline for the Evaluation and Management of Chronic Kidney Disease ${ }^{8}$ recently published by the KDIGO provides only minimal recommendations that are targeted specifically for the elderly. ${ }^{8}$

This guideline was ungraded, as it was based on expert opinion rather than evidence.

There are some unique issues in the management of hypertension in the elderly. These relate to the structural and functional changes associated with aging of the kidneys, which result in alterations of antihypertensive drug pharmacodynamics and pharmacokinetics. ${ }^{40}$ For instance, diuretics, particularly in the elderly, potentiate the BP-lowering effects of ACE inhibitors. ${ }^{37}$ In addition, the use of a combination of beta blockers and non-dihydropyridine calcium channel blockers should be avoided in the elderly in view of combined negative ionotropic and chronotropic effects. ${ }^{37}$ The use of peripheral alpha blockers is associated with urinary incontinence in older women, particularly if used with loop diuretics. ${ }^{41}$ However, most recommendations are based on expert opinion rather than evidence.

The American College of Cardiology and the American Heart Association recently produced consensus guidelines for the management of hypertension in the elderly, but these were based on limited clinical trials conducted among this population. ${ }^{42}$ These were reviewed with recommendations of BP targets of $<140 / 90 \mathrm{mmHg}$ if the individuals were aged $>65$ years, but up to $145 \mathrm{mmHg}$ systolic if over 80 years. ${ }^{43}$ Most patients will require more than one medication, but as single agents, diuretics and calcium channel blockers are some of the more effective drugs used in the elderly. ${ }^{43}$

\section{Salt restriction}

Although the benefits of salt restriction on hypertension have been established in the general population, the value 
of this approach has only just been explored in CKD. ${ }^{44,45}$ A double-blind, placebo-controlled, randomized crossover trial compared the effects of high and low salt intake on surrogate markers of CKD progression and cardiovascular risk in CKD patients. ${ }^{45}$ Those treated with salt restriction had a significantly lower BP and less proteinuria. The study included patients up to the age of 79 years. Larger, longer studies assessing hard outcomes, such as death and progression to dialysis requirement, are needed. The KDIGO guidelines on salt intake recommend lowering salt intake to $<90 \mathrm{mmol}$ ( $<2 \mathrm{~g}$ ) of sodium per day (corresponding to $5 \mathrm{~g}$ of sodium chloride) in adults, unless contraindicated. ${ }^{45}$

\section{Statins}

Key statin trials in the general population have included a varying number of older participants, ranging from none in the West of Scotland Coronary Prevention Study ${ }^{46}$ to $23 \%$ in the Scandinavian Simvastatin Survival study ${ }^{47}$ to $100 \%$ in the PROspective Study of Pravastatin in the Elderly at Risk trial. ${ }^{48}$

Statin trials in CKD have also been more inclusive of the elderly, with Die Deutsche Diabetes Dialyse Studie (4D) ${ }^{49}$ accepting patients up to 80 years, the Study of Heart And Renal Protection (SHARP) ${ }^{50}$ accepting those 40 years and older, and A Study to Evaluate the Use of Rosuvastatin in Subjects on Regular Hemodialysis: An Assessment of Survival and Cardiovascular Events (AURORA) ${ }^{51}$ including patients 50-80 years of age. Unfortunately, the outcomes of all these studies (except for the SHARP study) have been negative, and the use of statins in CKD remains controversial.

\section{Diabetes control}

The mainstays of treatment of diabetic nephropathy are good blood glucose control, BP control, and the use of ACE inhibitors or ARBs, but not the combination of these agents. However, these therapies - although proven in younger populations have not been validated in older populations. ${ }^{52}$ The KDIOGO guidelines recommend a target hemoglobin $\mathrm{A}_{1 \mathrm{c}}\left(\mathrm{HbA}_{1 \mathrm{c}}\right)$ of around $7.0 \%(53 \mathrm{mmol} / \mathrm{mol})$ to slow the progression diabetic $\mathrm{CKD}^{8}{ }^{8}$ These guidelines also recommend not targeting an $\mathrm{HbA}_{\mathrm{lc}}$ $<7.0 \%(<53 \mathrm{mmol} / \mathrm{mol})$ in patients at risk of hypoglycemia. The guidelines also indicate that target $\mathrm{HbA}_{1 \mathrm{c}}$ be extended above $7.0 \%(53 \mathrm{mmol} / \mathrm{mol})$ in patients with comorbidities, or limited life expectancy, and risk of hypoglycemia. The latter applies the control of diabetes in the elderly patient with $\mathrm{CKD} .{ }^{53}$

\section{Rehabilitation}

Rehabilitation can be effective in improving outcomes for elderly patients with CKD. Frailty is a common feature seen in the elderly patient with CKD. An exercise-based renal rehabilitation program can improve both physical function and mental health in patients with CKD up until the patients reach their early $70 s .{ }^{54}$ It is recommended that there should be routine assessment of physical function and recommendations for physical activity in older patients with CKD. ${ }^{55}$ The KDIGO guidelines recommend undertaking physical activity at a level appropriate for the patients' cardiovascular health and tolerance with a target of 30 minutes, five times per week. ${ }^{8}$

\section{Community support services}

Elderly patients with CKD are more likely to have limitations in their activities of daily living and require home care services. ${ }^{56}$ For those aged over 80 years, the initiation of dialysis was associated with reduced functional capacity requiring career support or nursing home care. ${ }^{57}$ Thus, the provision of such community support and home care is integral to the treatment of the elderly with $\mathrm{CKD}$ and requires consideration in health care planning.

\section{Anemia therapy}

Most of the studies assessing erythropoiesis-stimulating agents in the treatment of anemia in CKD have not included the elderly, particularly those over 75 years of age. ${ }^{58}$ For instance, the Trial to Reduce Cardiovascular Events with Aranesp Therapy study ${ }^{59}$ only included patients up to age 75 years of age. However, treatment with an erythropoiesisstimulating agents to improve quality of life is a reasonable option in the anemic elderly patient with CKD.

\section{Bicarbonate therapy}

Clinical trials have suggested that oral sodium bicarbonate may slow CKD progression. ${ }^{60}$ However, in the longest trial, conducted over 5 years, the mean age of patients was only 51 years, despite no specific exclusion criterion for the elderly participants. ${ }^{61} \mathrm{Cur}-$ rently, it is recommended that therapy be administered if serum bicarbonate is $<22 \mathrm{mmol} / \mathrm{L}$, but further large long-term clinical trials are required prior to it being used as routine therapy in CKD in order to slow progression. ${ }^{60}$

\section{Evolving therapies in CKD}

Unfortunately, it is disappointing that there are very few new therapies in clinical trials underway in CKD in general, let alone those that include the elderly.

\section{Antiaging}

A very recent proposal suggests that activating the sirtuin-1 enzyme, a nicotinamide adenine dinucleotide-dependent 
deacetylase, may play a role in preventing the diseases of aging such as cancer, Alzheimer's disease, and type 2 diabetes. ${ }^{62}$ Current activators include exercise and calorie restriction. A focus in the future on antiaging, rather than on specific diseases, may attenuate cancer and chronic diseases associated with aging. ${ }^{62}$ Resveratrol, found in red wine, is an activator of sirtuin-1, and synthetic, more potent activators are in development. These may prove to be important emerging therapies relevant to the prevention of age-related chronic diseases such as CKD. Perhaps this alternative pathway of research may also assist with treatments that prevent CKD.

\section{Antioxidants and anti- inflammatory agents}

It is now known that nontraditional risk factors such as oxidative stress and inflammation are involved in the progression of vascular disease as well as CKD. The nuclear factor E2-related factor 2 activators (such as bardoxolone methyl), which attenuate inflammation, initially showed promise at delaying the progression of CKD in type 2 diabetes with nephropathy in the Bardoxolone Methyl Treatment: Renal Function in CKD/Type 2 Diabetes study. ${ }^{63}$ However, when hard outcomes were assessed in the Bardoxolone Methyl Evaluation in Patients With Chronic Kidney Disease and Type 2 Diabetes trial, ${ }^{64}$ the study had to be terminated due to an excess of serious adverse events and mortality in the bardoxolone methyl-treated group. ${ }^{64}$ Perhaps with more careful selection of patients, such agents may still show promise as CKD therapies. Importantly, neither of these trials had an upper age limit for inclusion.

The role of allopurinol as a therapy in CKD is to be assessed in the CKD-FIX trial ${ }^{65}$ that is about to start in Australia along with New Zealand and Canada. This is a randomized controlled trial, and it will include the elderly, as all those aged $>18$ years are eligible..$^{65}$

\section{Medication prescribing in the elderly}

The elderly have diminished tolerance of medication side effects and, in addition, there is potentially inappropriate medication prescribing in the elderly. ${ }^{66}$

In the elderly, clinicians should avoid using potentially nephrotoxic medications such as nonsteroidal antiinflammatory agents (NSAIDs), nephrotoxic antibiotics such as aminoglycosides, the "triple whammy"67 (ACE inhibitors or ARBs combined with NSAIDs and diuretics) and radiographic contrast media.

\section{Dialysis}

Between 1992 and 2008, there was a substantial increase in the number of elderly patients accepted onto dialysis in Australia. ${ }^{2}$ However, this has plateaued over the last 4 years. The reasons for this are unclear, but a more realistic approach to the acceptance of the elderly onto dialysis might have occurred. The United States Renal Data System shows that the elderly $>65$ years are the most rapidly increasing group of the ESKD population. This is also the case in Europe. The Australian Institute of Health and Welfare data show that as many elderly people die with ESKD as those who are accepted onto dialysis. ${ }^{68}$ In Australia, there were 21,370 incident cases of ESKD between 2003-2007, a rate of 20.9/100,000 population; this was significantly higher among older people. There were similar numbers of patients treated with dialysis $(n=10,949)$ as those not treated with dialysis $(n=10,421)$, but treatment rates were influenced highly by age. More than $90 \%$ of people in all age groups between 5-60 years were treated, but this percentage decreased greatly for older people, with only $4 \%$ of people older than 85 years being treated.

The best timing of dialysis initiation has been investigated, and early initiation may be harmful ${ }^{69}$ and is certainly of no advantage. ${ }^{70}$

"Fistula First" ticed in younger patients, may not be the preferred approach for older patients because of their reduced life expectancy. A recent study in patients over 67 years of age found that mortality was similar for vascular grafts and fistulae created at the initiation of dialysis. ${ }^{72}$ However, there are significant risks and complications from vascular access catheters such as bacteremia, thrombosis, and higher mortality, if used for a long time.

Geriatric ESKD patients may benefit from home dialysis, as do their younger counterparts. The elderly may not receive timely ESKD care, and they are often subject to late referral. Between 2005-2008, only 43\% of older patients who initiated renal replacement therapy had experienced an outpatient nephrologist consultation over 1 year before starting treatment. ${ }^{73}$ A time-limited trial of dialysis may be appropriate in selected cases of older patients with ESKD.

\section{Clinical trials in dialysis}

It is also uncertain how applicable the quality of care and the desired clinical targets are to older patients with ESKD, as clinical trials in the dialysis population have also often excluded the elderly, particularly those over 75 years. Alternatively, sometimes it is not the specific age that has 
excluded these particular patients but, instead, other exclusion criteria. The hemodialysis (HEMO) study that assessed dialysis dose included patients up to the age of 80 years. ${ }^{74}$ The $4 \mathrm{D}^{49}$ and AURORA ${ }^{51}$ studies also accepted patients up to 80 years of age. The Initiating Dialysis Early and Late trial had no specific upper age limit and included patients up to age 74 years (mean: 62 years). ${ }^{70}$ In the EVOLVE study (Evaluation of Cinacalcet Hydrochloride Therapy to Lower Cardiovascular Events), which assessed the value of cinacalcet in hemodialysis patients, the mean age was 54 years, but despite no upper age limit, the oldest patients were 68 years. As with predialysis CKD, the clinical trials in dialysis should include the elderly to ensure that research can be translated into practice for the elderly should there be a positive outcome.

\section{Choosing dialysis or a conservative pathway supported by palliative care in the elderly patient with CKD}

There has been great interest recently in ensuring patients consider the implications of dialysis therapy at an advanced age, especially if they have associated comorbidities. ${ }^{75}$ Thus, where possible, once a patient's eGFR level falls below $20 \mathrm{~mL} /$ minute $/ 1.73 \mathrm{~m}^{2}$, consideration should be given to discussing advanced care planning and constructing an advanced care directive. Along with this, the nephrologist should enter discussions with the patient regarding his/her prognosis using one of the available tools, such as the surprise question. ${ }^{76}$ The key requirement is to participate in shared decision making with the patient. A retrospective study by Murtagh et $\mathrm{al}^{77}$ showed that for ESKD patients $>75$ years with two or more comorbidities, the survival rate was not dissimilar, whether the patients had dialysis or supportive care. Nursing home residents in the US had a very high mortality rate and significant loss of physical function over 12 months after starting dialysis. ${ }^{78}$ Overall, careful shared decision making with a focus on symptom control and palliative care are reasonable options for the elderly patient with CKD, particularly if they have multiple comorbidities.

\section{Withdrawal from dialysis}

Withdrawal of dialysis is the commonest cause of death for dialysis patients aged 65-74 and over 75 in Australia. ${ }^{79}$ With good advanced care planning and advanced care directives that are regularly updated when the health of the elderly patient on dialysis deteriorates, a discussion regarding withdrawal of dialysis therapy is much easier. Once confirmed, such decisions are supported by symptom control and palliative care. Common symptoms include nausea, vomiting, shortness of breath, pain, and excessive secretions in the respiratory tract. There are guidelines that specifically address the management of symptoms in this setting. ${ }^{80}$

\section{Kidney transplantation}

Recipient age can be an appropriate consideration in the allocation of deceased donor kidneys. Transplant coordinators can allocate "marginal donors" with elderly recipients. However, advanced age is not an absolute contraindication for kidney transplantation. ${ }^{81}$ Kidney transplantation may provide the elderly with good long-term graft survival and quality of life, but they have a higher risk of cancer, infection, and cardiovascular disease than their younger counterparts. ${ }^{81}$

In a single-center study of 984 patients referred for kidney transplantation, only 123 patients were over 65 years of age and only half were deemed suitable for transplantation. ${ }^{82}$ Those excluded had comorbidities such as coronary artery disease or poor mobility. Another recent retrospective cohort study reported graft and patient survival in kidney transplant recipients over 60 years of age. ${ }^{83}$ The graft and patient survivals were acceptable, indicating that kidney transplantation can be performed in the elderly after appropriate clinical scrutiny. Deaths with a functioning graft accounted for $79.5 \%$ of grafts lost.

Overall, kidney transplantation is associated with improved life expectancy and quality of life at all ages. ${ }^{84}$ Biological age, rather than chronological age, has been suggested as more important in considering kidney transplantation. ${ }^{85}$ Placing elderly ESKD patients over 65 years of age on transplant waiting lists has increased by a factor of five over the last 20 years. ${ }^{86}$ The immune system of the elderly undergoes immunosenescence,

Table I Factors that amplify complexities in elder care

Visual impairment
Hearing loss
Social issues
Financial problems
Malnutrition
Isolation
Altered cognitive function
Reduced functional status
Risk of falls
Unsteady gait
Urinary and/or fecal incontinence
Structural safety issues in the home
Spiritual issues
Family issues
Anxiety and depression
Effects of multiple medications

Hearing loss

Social issues

Financial problems

Malnutrition

Isolation

Unsteady gait

Urinary and/or fecal incontinence

Structural safety issues in the home

Spiritual issues

Anxiety and depression

multiple medications 
which may protect the patient from rejection, but it increases risk of infection and cancer. ${ }^{87}$ Therefore, the type and dose of immunosuppressive medication may need to be adjusted. ${ }^{88}$ However, even though there is an increased risk of death from infection, the risk is higher in waitlisted patients than in those who receive a kidney transplant. ${ }^{89}$

The presence of comorbidities, frailty, and functional impairment limit the number of elderly patients suitable for wait listing for transplant, but those selected may have a reasonable life expectancy and quality of life..$^{87}$

\section{Conclusion}

The provision of therapies for the elderly with CKD is limited by the exclusion of such age groups from clinical trials and the paucity of specific interventions available. Most clinical guidelines extrapolate from outcomes that are determined from younger populations. The elderly require special consideration in many areas because of their frequent comorbidities, frailty, social isolation, and financial limitations. However, recent research has focused on the transition of the elderly onto dialysis and has emphasized the necessity to consider alternatives such as a conservative pathway supported by palliative care, rather than dialysis, for those with significant comorbidities. Kidney transplantation can be successful in carefully selected elderly patients. Overall, inclusion of the elderly in future clinical trials will greatly improve our ability to translate research into practice for this patient group.

\section{Disclosure}

The author reports no conflicts of interest in this work.

\section{References}

1. Australian Bureau of Statistics (2005). Population Projections: 2004-2010. Available from: http://www.abs.gov.au/ausstats/abs@. nsf/Lookup/by\%20Subject/1370.0 2010 Chapter Population\%20 projections\%20(3.4). Accessed January 1, 2014.

2. Grace B, Hurst K, McDonald S. Chapter 2: New patients commencing treatment in 2011. In: 2012 Annual Report - 35th Edition. ANZDATA Registry: Adelaide, Australia; 2012.

3. USRDS. 2011 Annual Data Report. Atlas of Chronic Disease and End Stage Renal Disease in the United States, 2011. Available from: http:// www.ajkd.org/issues?issue_key=S0272-6386\%2811\%29X0015-X. Accessed January 1, 2014.

4. Kramer A, Stel V, Zoccali C, et al; ERA-EDTA Registry. An update on renal replacement therapy in Europe: ERA-EDTA Registry data from 1997 to 2006. Nephrol Dial Transplant. 2009;24(12):3557-3566.

5. Locatelli F, Pozzoni P. Chronic kidney disease in the elderly: is it really a premise for overwhelming renal failure? Kidney Int. 2006;69(12): $2118-2120$.

6. Bowling CB, Muntner P. Epidemiology of chronic kidney disease among older adults: a focus on the oldest old. J Gerontol A Biol Sci Med Sci. 2012;67(12):1379-1386.

7. The Australian Institute of Health and Welfare. Australia's Health 2012. Canberra, Australia: Australian Institute of Health and Welfare; 2012.
8. Kidney Disease: Improving Global Outcomes (KDIGO) CKD Work Group. KDIGO clinical practice guideline for the evaluation and management of chronic kidney disease. Kidney Int. 2013; Suppl 3(4):1-150.

9. Dousdampanis P, Trigka K, Fourtounas C. Diagnosis and management of chronic kidney disease in the elderly: a field of ongoing debate. Aging Dis. 2012;3(5):360-372.

10. Johnson DW, Jones GR, Mathew TH, et al; Australasian Proteinuria Consensus Working Group. Chronic kidney disease and measurement of albuminuria or proteinuria: a position statement. Med J Aust. 2012;197(4):224-225.

11. Hallan SI, Matsushita K, Sang Y, et al; Chronic Kidney Disease Prognosis Consortium. Age and association of kidney measures with mortality and end-stage renal disease. JAMA. 2012;308(22):2349-2360.

12. Kidney Health Australia [webpage on the Internet]. Chronic Kidney Disease (CKD) Management in General Practice. Melbourne, Australia: Kidney Health Australia; 2012. Available from: http://www.kidney. org.au//LinkClick.aspx?fileticket=vfDcA4sEUMs\%3d\&tabid=635\& mid=1584. Accessed January 1, 2014.

13. Grams ME, Chow EK, Segev DL, Coresh J. Lifetime incidence of CKD stages 3-5 in the United States. Am J Kidney Dis. 2013;62(2): $245-252$.

14. Hemmelgarn BR, Zhang J, Manns BJ, et al. Progression of kidney dysfunction in the community-dwelling elderly. Kidney Int. 2006;69(12): 2155-2161.

15. Lindeman RD, Tobin J, Shock NW. Longitudinal studies on the rate of decline in renal function with age. J Am Geriatr Soc. 1985;33(4): $278-285$.

16. Lamb EJ, O'Riordan SE, Delaney MP. Kidney function in older people: pathology, assessment and management. Clin Chim Acta. 2003; 334(1-2):25-40.

17. Drenth-van Maanen AC, Jansen PA, Proost JH, et al. Renal function assessment in older adults. Br J Clin Pharmacol. 2013;76(4): 616-623.

18. Flamant M, Haymann JP, Vidal-Petiot E, et al. GFR estimation using the Cockcroft-Gault, MDRD study, and CKD-EPI equations in the elderly. Am J Kidney Dis. 2012;60(5):847-849.

19. Venuthurupalli SK, Hoy WE, Healey HG, Salisbury A, Fassett RG; CKD.QLD group. CKD.QLD: chronic kidney disease surveillance and research in Queensland, Australia. Nephrol Dial Transplant. 2012;27 Suppl 3:iii139-iii145.

20. Lash JP, Go AS, Appel LJ, et al; Chronic Renal Insufficiency Cohort (CRIC) Study Group. Chronic Renal Insufficiency Cohort (CRIC) Study: baseline characteristics and associations with kidney function. Clin J Am Soc Nephrol. 2009;4(8):1302-1311.

21. Levin A, Rigatto C, Brendan B, et al; CanPREDDICT investigators. Cohort profile: Canadian study of prediction of death, dialysis and interim cardiovascular events (CanPREDDICT). BMC Nephrol. 2013;14:121.

22. McCullough PA, Vassalotti JA, Collins AJ, Chen SC, Bakris GL, Whaley-Connell AT. National Kidney Foundation's Kidney Early Evaluation Program (KEEP) annual data report 2010: executive summary. Am J Kidney Dis. 2011;57(3 Suppl 2):S1-S3.

23. Spanaus KS, Kollerits B, Ritz E, Hersberger M, Kronenberg F, von Eckardstein A; Mild and Moderate Kidney Disease (MMKD) Study Group. Serum creatinine, cystatin C, and beta-trace protein in diagnostic staging and predicting progression of primary nondiabetic chronic kidney disease. Clin Chem. 2010;56(5):740-749.

24. Landray MJ, Emberson JR, Blackwell L, et al. Prediction of ESRD and death among people with CKD: the Chronic Renal Impairment in Birmingham (CRIB) prospective cohort study. Am J Kidney Dis. 2010;56(6):1082-1094.

25. Marks A, Macleod C, McAteer A, et al. Chronic kidney disease, a useful trigger for proactive primary care? Mortality results from a large UK cohort. Fam Pract. 2013;30(3):282-289.

26. Nair R, Bell JM, Walker PD. Renal biopsy in patients aged 80 years and older. Am J Kidney Dis. 2004;44(4):618-626. 
27. Rothwell PM. External validity of randomised controlled trials: "to whom do the results of this trial apply?". Lancet. 2005;365(9453):82-93.

28. Cho S, Lau SW, Tandon V, Kumi K, Pfuma E, Abernethy DR. Geriatric drug evaluation: where are we now and where should we be in the future? Arch Intern Med. 2011;171(10):937-940.

29. Talarico L, Chen G, Pazdur R. Enrollment of elderly patients in clinical trials for cancer drug registration: a 7-year experience by the US Food and Drug Administration. J Clin Oncol. 2004;22(22):4626-4631.

30. Cherubini A, Del Signore S, Ouslander J, Semla T, Michel JP. Fighting against age discrimination in clinical trials. JAm Geriatr Soc. 2010;58(9):1791-1796.

31. Boyd CM, Darer J, Boult C, Fried LP, Boult L, Wu AW. Clinical practice guidelines and quality of care for older patients with multiple comorbid diseases: implications for pay for performance. JAMA. 2005;294(6):716-724.

32. Vitry AI, Zhang Y. Quality of Australian clinical guidelines and relevance to the care of older people with multiple comorbid conditions. Med J Aust. 2008;189(7):360-365.

33. Hilmer SN, McLachlan AJ, Le Couteur DG. Clinical pharmacology in the geriatric patient. Fundam Clin Pharmacol. 2007;21(3):217-230.

34. Hubbard RE, O'Mahony MS, Woodhouse KW. Medication prescribing in frail older people. Eur J Clin Pharmacol. 2013;69(3):319-326.

35. Randomised placebo-controlled trial of effect of ramipril on decline in glomerular filtration rate and risk of terminal renal failure in proteinuric, non-diabetic nephropathy. The GISEN Group (Gruppo Italiano di Studi Epidemiologici in Nefrologia). Lancet. 1997;349(9069): 1857-1863.

36. Parving HH, Lehnert H, Bröchner-Mortensen J, Gomis R, Andersen S, Arner P; Irbesartan in Patients with Type 2 Diabetes and Microalbuminuria Study Group. The effect of irbesartan on the development of diabetic nephropathy in patients with type 2 diabetes. $N$ Engl J Med. 2001;345(12):870-878.

37. Bakris GL, Williams M, Dworkin L, et al. Preserving renal function in adults with hypertension and diabetes: a consensus approach. National Kidney Foundation Hypertension and Diabetes Executive Committees Working Group. Am J Kidney Dis. 2000;36(3):646-661.

38. Kovesdy CP, Bleyer AJ, Molnar MZ, et al. Blood pressure and mortality in US veterans with chronic kidney disease: a cohort study. Ann Intern Med. 2013;159(4):233-242.

39. Marcum ZA, Fried LF. Aging and antihypertensive medication-related complications in the chronic kidney disease patient. Curr Opin Nephrol Hypertens. 2011;20(5):449-456.

40. Zhou XJ, Rakheja D, Yu X, Saxena R, Vaziri ND, Silva FG. The aging kidney. Kidney Int. 2008;74(6):710-720.

41. Peron EP, Zheng Y, Perera S, et al; Health, Aging, and Body Composition (Health ABC) Study. Antihypertensive drug class use and differential risk of urinary incontinence in community-dwelling older women. J Gerontol A Biol Sci Med Sci. 2012;67(12):1373-1378.

42. Aronow WS, Fleg JL, Pepine CJ, et al; ACCF Task Force. ACCF/AHA 2011 expert consensus document on hypertension in the elderly: a report of the American College of Cardiology Foundation Task Force on Clinical Expert Consensus Documents. Circulation. 2011;123(21): 2434-2506.

43. Oliva RV, Bakris GL. Management of hypertension in the elderly population. J Gerontol A Biol Sci Med Sci. 2012;67(12):1343-1351.

44. McMahon EJ, Bauer JD, Hawley CM, et al. The effect of lowering salt intake on ambulatory blood pressure to reduce cardiovascular risk in chronic kidney disease (LowSALT CKD study): protocol of a randomized trial. BMC Nephrol. 2012;13:137.

45. McMahon EJ, Bauer JD, Hawley CM, et al. A randomized trial of dietary sodium restriction in CKD. J Am Soc Nephrol. 2013;24(12): 2096-2103.

46. Shepherd J, Cobbe SM, Ford I, et al. Prevention and coronary heart disease with pravastatin in men with hypercholesterolemia. West of Scotland Coronary Prevention Study Group. $N$ Engl J Med. 1995;333(20):1301-1307.
47. Randomised trial of cholesterol lowering in 4444 patients with coronary heart disease: the Scandinavian Simvastatin Survival Study (4S). Lancet. 1994;344(8934):1383-1389.

48. Shepherd J, Blauw GJ, Murphy MB, et al; PROPSER study group. PROspective Study of Pravastatin in the Elderly at Risk. Pravastatin in elderly individuals at risk of vascular disease (PROSPER): a randomised controlled trial. Lancet. 2002;360(9346):1623-1630.

49. Wanner C, Krane V, März W, et al; German Diabetes and Dialysis Study Investigators. Atorvastatin in patients with type 2 diabetes mellitus undergoing hemodialysis. N Engl J Med. 2005;353(3):238-248.

50. Baigent $C$, Landray MJ, Reith C, et al; SHARP Investigators. The effects of lowering LDL cholesterol with simvastatin plus ezetimibe in patients with chronic kidney disease (Study of Heart and Renal Protection): a randomised placebo-controlled trial. Lancet. 2011;377(9784): 2181-2192.

51. Fellström BC, Jardine AG, Schmieder RE, et al; AURORA Study Group. Rosuvastatin and cardiovascular events in patients undergoing hemodialysis. N Engl J Med. 2009;360(14):1395-1407.

52. Williams ME. Diabetic kidney disease in elderly individuals. Med Clin North Am. 2013;97(1):75-89.

53. Brown AF, Mangione CM, Slabia D, Sarkisian CA; California Healthcare Foundation/American Geriatrics Society Panel on Improving Care for Elders with Diabetes. Guidelines for improving the care of the older person with diabetes mellitus. J Am Geriatr Soc. 2003; 51(5 Suppl Guidelines):S265-S280.

54. Greenwood SA, Lindup H, Taylor K, et al. Evaluation of a pragmatic exercise rehabilitation programme in chronic kidney disease. Nephrol Dial Transplant. 2012;27 Suppl 3:iii126-iii134.

55. Painter P, Marcus RL. Assessing physical function and physical activity in patients with CKD. Clin J Am Soc Nephrol. 2013;8(5):861-872.

56. Gopinath B, Harris DC, Burlutsky G, Mitchell P. Use of community support services and activity limitations among older adults with chronic kidney disease. J Gerontol A Biol Sci Med Sci. 2013;68(6): 741-747.

57. Jassal SV, Chiu E, Hladunewich M. Loss of independence in patients starting dialysis at 80 years of age or older. $N$ Engl J Med. 2009;361(16): 1612-1613.

58. Palmer SC, Navaneethan SD, Craig JC, et al. Meta-analysis: erythropoiesis-stimulating agents in patients with chronic kidney disease. Ann Intern Med. 2010;153(1):23-33.

59. Pfeffer MA, Burdmann EA, Chen CY, et al; TREAT Investigators. A trial of darbepoetin alfa in type 2 diabetes and chronic kidney disease. N Engl J Med. 2009;361(21):2019-2032.

60. Loniewski I, Wesson DE. Bicarbonate therapy for prevention of chronic kidney disease progression. Kidney Int. Epub October 9, 2013.

61. Mahajan A, Simoni J, Sheather SJ, Broglio KR, Rajab MH, Wesson DE. Daily oral sodium bicarbonate preserves glomerular filtration rate by slowing its decline in early hypertensive nephropathy. Kidney Int 2010;78(3):303-309.

62. Hubbard BP, Gomes AP, Dai H, et al. Evidence for a common mechanism of SIRT1 regulation by allosteric activators. Science. 2013; 339(6124):1216-1219.

63. Pergola PE, Raskin P, Toto RD, et al; BEAM Study Investigators. Bardoxolone methyl and kidney function in CKD with type 2 diabetes. N Engl J Med. 2011;365(4):327-336.

64. Reata Pharmaceuticals [webpage on the Internet]. Company statement: termination of the BEACON trial. Irving, TX: Reata Pharmaceuticals; 2012. Available from: http://www.reatapharma.com/investors-media/ news/news-timeline/2012/company-statement-termination-of-beacontrial.aspx. Accessed January 1, 2014.

65. Australasian Kidney Trials Network [webpage on the Internet]. The CKD-FIX study: a randomised Controlled trial of slowing of Kidney Disease progression From the Inhibition of Xanthine oxidase. Queensland, Australia: Australasian Kidney Trials Network; 2012. Available from: http://www.aktn.org.au/trials/development.php\#CKD_ FIX. Accessed. 
66. Jones SA, Bhandari S. The prevalence of potentially inappropriate medication prescribing in elderly patients with chronic kidney disease. Postgrad Med J. 2013;89(1051):247-250.

67. Thomas MC. Diuretics, ACE inhibitors and NSAIDs - the triple whammy. Med J Aust. 2000;172(4):184-185.

68. Sparke C, Moon L, Green F, et al. Estimating the total incidence of kidney failure in Australia including individuals who are not treated by dialysis or transplantation. Am J Kidney Dis. 2013;61(3):413-419.

69. Rosansky SJ, Eggers P, Jackson K, Glassock R, Clark WF. Early start of hemodialysis may be harmful. Arch Intern Med. 2011;171(5): 396-403.

70. Cooper BA, Branley P, Bulfone L, et al; IDEAL Study. A randomized, controlled trial of early versus late initiation of dialysis. $N$ Engl J Med. 2010;363(7):609-619.

71. Vassalotti JA, Jennings WC, Beathard GA, et al; Fistula First Breakthrough Initiative Community Education Committee. Fistula first breakthrough initiative: targeting catheter last in fistula first. Semin Dial. 2012;25(3):303-310.

72. DeSilva RN, Patibandla BK, Vin Y, et al. Fistula first is not always the best strategy for the elderly. J Am Soc Nephrol. 2013;24(8):1297-1304.

73. Winkelmayer WC, Kurella Tamura M. Predialyis nephrology care of older individuals approaching end-stage renal disease. Semin Dial. 2012;25(6):628-632.

74. Eknoyan G, Beck GJ, Cheung AK, et al; Hemodialysis (HEMO) Study Group. Effect of dialysis dose and membrane flux in maintenance hemodialysis. N Engl J Med. 2002;347(25):2010-2019.

75. Fassett RG, Robertson IK, Mace R, Youl L, Challenor S, Bull R. Palliative care in end-stage kidney disease. Nephrology (Carlton). 2011;16(1):4-12.

76. Moss AH, Ganjoo J, Sharma S, et al. Utility of the "surprise" question to identify dialysis patients with high mortality. Clin J Am Soc Nephrol. 2008;3(5):1379-1384.

77. Murtagh FE, Marsh JE, Donohoe P, Ekbal NJ, Sheerin NS, Harris FE. Dialysis or not? A comparative survival study of patients over 75 years with chronic kidney disease stage 5. Nephrol Dial Transplant. 2007;22(7):1955-1962.

78. Kurella Tamura M, Covinsky KE, Chertow GM, Yaffe K, Landefeld CS, McCulloch CE. Functional status of elderly adults before and after initiation of dialysis. N Engl J Med. 2009;361(16):1539-1547.
79. McDonald S. Chapter 3: Deaths. In: 2012 Annual Report-35th Edition. ANZDATA Registry: Adelaide, Australia; 2012. Available from: http:// www.anzdata.org.au/anzdata/AnzdataReport/35thReport/2012c03 _deaths_v2.9.pdf. Accessed January 1, 2014.

80. Douglas C, Murtagh FE, Chambers EJ, Howse M, Ellershaw J. Symptom management for the adult patient dying with advanced chronic kidney disease: a review of the literature and development of evidence-based guidelines by a United Kingdom Expert Consensus Group. Palliat Med. 2009;23(2):103-110.

81. Impedovo SV, Ditonno P, Ricapito V, et al. Advanced age is not an exclusion criterion for kidney transplantation. Transplant Proc. 2013; 45(7):2650-2653.

82. Lenihan CR, Hurley MP, Tan JC. Comorbidities and kidney transplant evaluation in the elderly. Am J Nephrol. 2013;38(3):204-211.

83. Rodelo JR, Nieto-Ríos JF, Serna-Higuita LM, et al. Survival of renal transplantation patients older than 60 years: a single-center experience. Transplant Proc. 2013;45(4):1402-1409.

84. Rao PS, Merion RM, Ashby VB, Port FK, Wolfe RA, Kayler LK. Renal transplantation in elderly patients older than 70 years of age: results from the Scientific Registry of Transplant Recipients. Transplantation. 2007;83(8):1069-1074.

85. Danovitch G, Savransky E. Challenges in the counseling and management of older kidney transplant candidates. Am J Kidney Dis. 2006; 47(4 Suppl 2):S86-S97.

86. USRDS. 2012 Annual Data Report: Annual Data Report. Atlas of Chronic Disease and End Stage Renal Disease in the United States, 2012.

87. Keith DS. Transplantation in the elderly patient. Clin Geriatr Med. 2013;29(3):707-719.

88. Singh P, Germain MJ, Cohen L, Unruh M. The elderly patient on dialysis: geriatric considerations. Nephrol Dial Transplant. Epub June 19, 2013.

89. Meier-Kriesche HU, Ojo AO, Hanson JA, Kaplan B. Exponentially increased risk of infectious death in older renal transplant recipients. Kidney Int. 2001;59(4):1539-1543.
Clinical Interventions in Aging

\section{Publish your work in this journal}

Clinical Interventions in Aging is an international, peer-reviewed journal focusing on evidence-based reports on the value or lack thereof of treatments intended to prevent or delay the onset of maladaptive correlates of aging in human beings. This journal is indexed on PubMed Central, MedLine, the American Chemical Society's 'Chemical Abstracts

\section{Dovepress}

Service' (CAS), Scopus and the Elsevier Bibliographic databases. The manuscript management system is completely online and includes a very quick and fair peer-review system, which is all easy to use. Visit http://www.dovepress.com/testimonials.php to read real quotes from published authors. 